\title{
Optimal Management of Gastric Outlet Obstruction in Unresectable Malignancies
}

\author{
Stephanie Lok Hang Cheung and Anthony Yuen Bun Teoh \\ Department of Surgery, Prince of Wales Hospital, The Chinese University of Hong Kong, Hong Kong Special Administrative Region, \\ China
}

Article Info

Received January 13, 2021

Revised March 17, 2021

Accepted March 26, 2021

Published online May 31, 2021

Corresponding Author

Anthony Yuen Bun Teoh

ORCID https://orcid.org/0000-0002-1885-8035

E-mail anthonyteoh@surgery.cuhk.edu.hk

\begin{abstract}
The aim of this article is to review the different treatment options for malignant gastric outlet obstruction (GOO) and compare their safety and efficacy. We describe the history and evolution of gastrojejunostomy (GJ), endoscopic stenting and endoscopic ultrasonography-guided gastroenterostomy (EUS-GE) and analyze the current evidence regarding these three methods available in the literature, comparing their applicability, safety, complications and cost when used for the treatment of malignant GOO. We conclude that given the benefits of endoscopic techniques and the ability to place a stent away from the tumor, EUS-GE is a promising technique that may yield an efficacy similar to that of surgical GJ and duodenal stenting, with lower reintervention rates and fewer adverse events. (Gut Liver 2022;16:190-197)
\end{abstract}

Key Words: Gastric outlet obstruction; Stents; Palliative care; Stomach neoplasm; Gastroenterostomy

\section{INTRODUCTION}

Malignant gastric outlet obstruction (GOO) is the mechanical obstruction to gastric emptying often caused by malignancies of the stomach, duodenum or periampullary cancers. Patients with GOO often suffer from symptoms such as vomiting, nausea and reduced appetite which reduces the patient's quality of life. GOO usually occurs when the malignancy is at an advanced stage and the aim of treatment is usually to palliate and re-establish oral intake to improve the quality of life.

Many factors play a role in the management of malignant GOO including the patient's functional performance, stage of cancer, prognosis and quality of life. Currently available options include surgical gastrojejunostomy (GJ) and endoscopic stenting. Recently, endoscopic ultrasonography-guided gastroenterostomy (EUS-GE) with a lumenapposing self-expandable metal stent (LAMS) has also been developed. ${ }^{1}$ This article aims to discuss the different treatment options for malignant GOO and compare their safety and efficacy.

\section{SURGICAL GASTROJEJUNOSTOMY}

Laparoscopic GJ (LGJ) is the standard for creating gastric bypass in malignant GOO and the procedure has been proven to be associated with better morbidity and mortality rates as compared to the open approach (Fig. 1). Studies

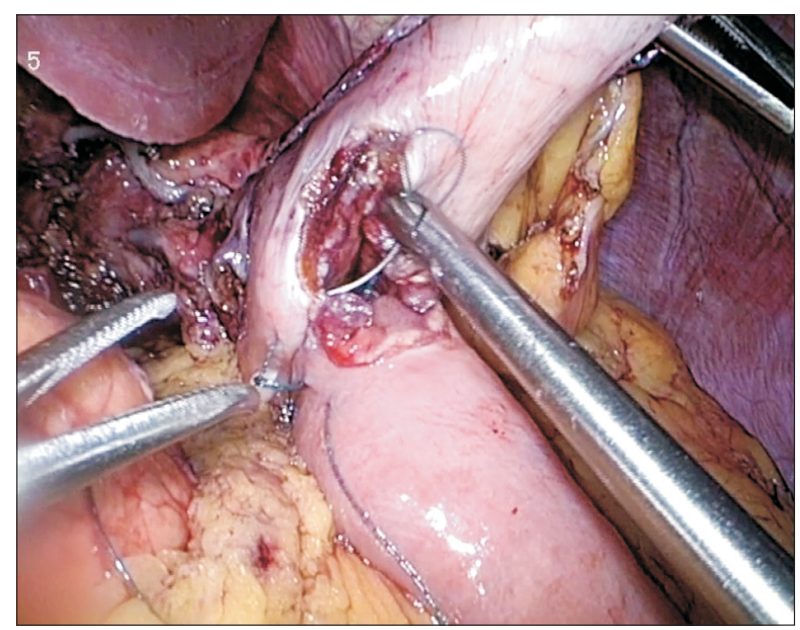

Fig. 1. Laparoscopic gastrojejunostomy. 
have also showed lower rates of delayed gastric emptying and faster resumption of oral feeding with the laparoscopic technique. ${ }^{2}$ There are two main techniques in performing an LGJ, ${ }^{3}$ namely the antecolic and retrocolic method. The antecolic method is more commonly used as the retrocolic method is associated with a higher risk of internal herniation and absence of definite advantages. During the procedure, the gastrocolic omentum is first opened and the lesser sac entered to identify the distal stomach. A loop of small bowel 30 to $50 \mathrm{~cm}$ distal to the ligament of Treitz is then chosen for the GJ. Enterotomies are made with cautery in both the jejunum and stomach and a surgical stapler is then inserted into the enterotomies to create the anastomosis. The common enterotomy is then closed with sutures.

The major complications of LGJ include postoperative bleeding, anastomotic leak, delayed gastric emptying, and postoperative ileus. ${ }^{3}$ The procedure also possesses several advantages over open GJ (OGJ). Several studies have found that patients undergoing LGJ have a shorter median hospital stay with a difference of up to 10 days, shorter time to solid food intake (difference of 2 days), ${ }^{4}$ lower intraoperative blood loss, ${ }^{4}$ and reduced use of opiate analgesic. ${ }^{5,6}$

\section{DUODENAL STENT}

The first report of endoscopic self-expandable metallic stent (SEMS) placement for malignant GOO was published in $1992 .{ }^{7}$ Nowadays, endoscopic stenting is a largely popular alternative to surgical GJ, especially for patients who are not fit for surgery, patients who have recurrence of symptoms after surgery or patients with poorer prognosis (Fig.

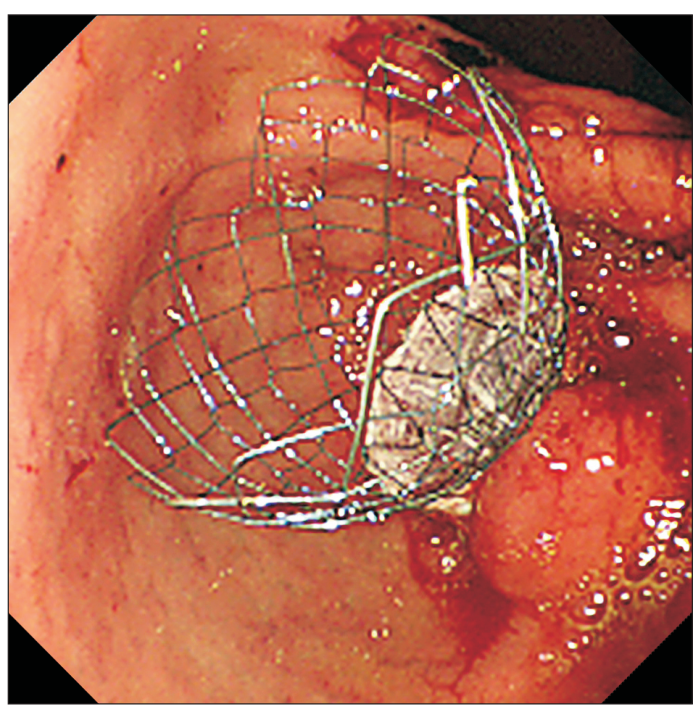

Fig. 2. Duodenal stenting with a partially covered duodenal stent.
2). The reported clinical success rate ranges between $84 \%$ and $93 \%$ with technical success between $93 \%$ and $97 \%{ }^{8}$

Careful selection of patients and evaluation of types of duodenal stricture is required before proceeding with duodenal stenting. Duodenal strictures are evaluated by endoscopy and also injection of contrast above the stricture and immediately downstream of stricture to assess morphology, length and degree of obstruction.

There are different types of duodenal stents available. SEMS consist of woven, knitted or laser cut metal mesh that exerts self-expanding forces until they reach maximum fixed diameter. SEMS are usually loaded inside a delivery device in a compressed form, passed to and deployed at the stricture site endoscopically under fluoroscopic guidance, and self-expand in around 24 to 48 hours.

Important characteristics of a stent include radial force which is the expanding force, and axial force which is the recovery force that keeps the stent straight after it is placed. ${ }^{9}$ The radial force is more important as this force keeps the gastric opening patent and prevent recurrence of GOO. Braided stents usually have a relatively low radial force $(<150 \mathrm{~N})$ that gradually decreased to $0 \mathrm{~N}$ during expansion, whereas plastic and metal stents that are nonbraided manner usually have an initially high radial force $(>300 \mathrm{~N})$ followed by a steep decline to $0 \mathrm{~N}$ during expansion. The opposite is shown when comparing axial forces, where axial force was relatively high for braided SEMSs $(>1.5 \mathrm{~N})$, whereas non-braided SEMSs showed a much lower peak axial force $(<1.5 \mathrm{~N}) .^{10}$

There are mainly two types of stents: uncovered and covered stents, with their use depending on patient related variables, e.g., location of stenosis, involvement of bile duct and patient's nutritional status. ${ }^{11}$ Uncovered stents reduce the risk of migration due to better tissue anchorage, and provides more flexibility thus can follow duodenal angulations more closely. Uncovered stents also allow for bile to flow through the stent interstices, so is more indicated in patients with previously placed biliary stents. However, these stents exert more pressure especially on acute angled stenosis which will cause mucosal hyperplasia and tissue ingrowth. ${ }^{11}$ Covered stents can be employed to treat tissue ingrowth into an uncover SEMS. The advantage is the prevention of recurrent obstruction but the disadvantage is a higher risk of stent migration which may cause intestinal obstruction requiring surgical interventions in the case of complete migration. Other disadvantages include relatively rigidity of stent and a higher cost. ${ }^{12}$ However, two randomized trials comparing covered and uncovered stents by Kim et al. ${ }^{13}$ and Maetani et al. ${ }^{14}$ have previously showed that there is no difference in stent patency or inpatient survival; with covered stents associated with a higher incidence of 
stent migration, and uncovered stents with a higher rate of tumor ingrowth.

The common complications of both types of duodenal stents include tumor overgrowth, ingrowth, food impaction, stent migration and biliary obstruction. Endoscopic intervention is usually needed in $20 \%$ to $25 \%$ of patients who develop complications. Rarer but more fatal complications can include bleeding and bowel wall perforation due to bare metal ends of stents. ${ }^{8,15}$

\section{ENDOSCOPIC ULTRASONOGRAPHY- GUIDED GASTROENTEROSTOMY}

EUS-GE was first described in 2002. ${ }^{16}$ It has recently emerged as an alternative to both stenting and surgical gastroenterostomy for the treatment of malignant GOO. There are different types of technique for performing EUSGE. ${ }^{17}$ All methods aim to create an EUS-guided bypass by inserting a LAMS from the gastric lumen to the small bowel distal to the obstruction. Systemic review has found that the technical and clinical success of EUS-GE is $93 \%$ and $91 \%$ respectively. ${ }^{18}$ Reintervention rate is $11.5 \%$. Some complications from EUS-GE include peritonitis, perforation, abdominal pain and bleeding, with rates up to $11 \%{ }^{18}$

\section{Direct method}

A duodenal tube is first inserted distal to the obstruction under endoscopic guidance (Fig. 3A). Diluted con- trast is then injected into the duodenum and jejunum to distend the lumen. A linear echoendoscope is inserted into stomach identifying a duodenal or jejunal loop next to the stomach. EUS-guided transgastric puncture is then performed by the direct method using a cautery enhanced LAMS. The distal anchoring flange is deployed under EUS and fluoroscopic guide while the proximal flange is then deployed under endoscopic guidance. Avoidance in using a guidewire also reduces the chance of pushing the jejunum away during LAMS deployment. ${ }^{1,19}$

\section{Balloon assisted methods}

This method uses a retrieval/dilating balloon, single balloon overtube, nasobiliary drain and ultraslim endoscope (Fig. 3B, D, E). The area of stenosis is traversed by the endoscope itself or by guidewire under fluoroscopic guidance. $^{20}$ The downstream method is where a large contrast filled balloon is placed in the jejunum using a guidewire, the inflated balloon is then located endosonographically and a transgastric puncture is performed with a needle with the goal of bursting the balloon and securing its position in the small bowel. A guidewire is then passed through the needle and the LAMS is deployed over this wire. This method is the basis of multiple other techniques including (1) the rendezvous method where the guidewire is pulled back through the duodenum obstruction and out of the mouth, then the LAMS is deployed over the guidewire; (2) the retrograde method where after the needle puncture and guidewire passage, a therapeutic endoscope is used to

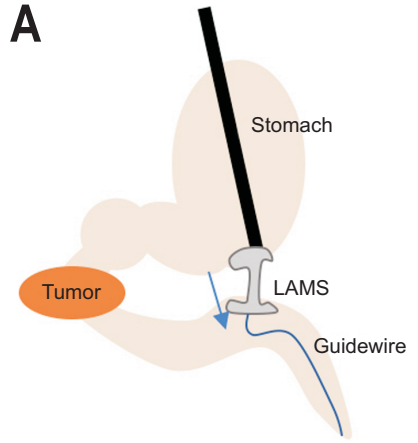

D

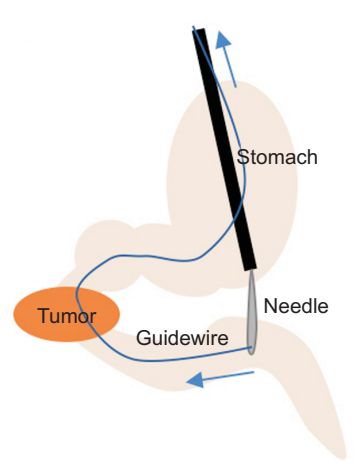

B

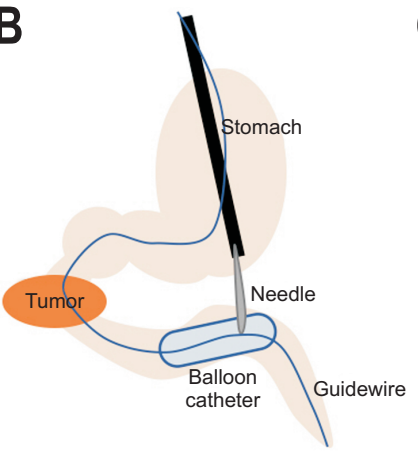

E

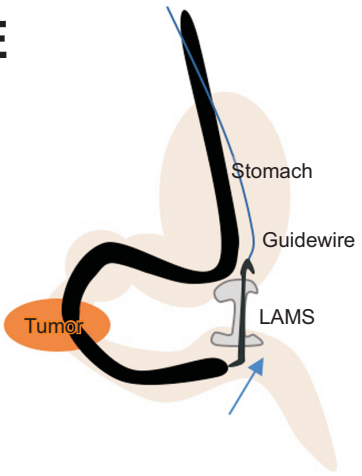

C

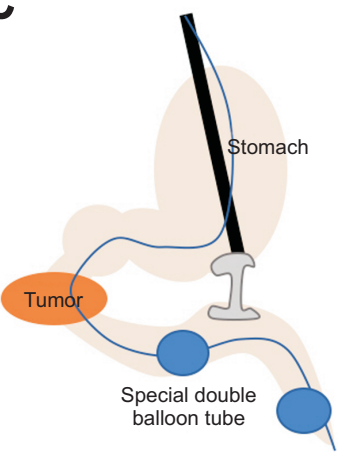

Fig. 3. (A) Direct method. (B) Balloon assisted method. (C) Endoscopic ultrasonography-guided balloonoccluded gastrojejunostomy bypass method. (D) The rendezvous method. (E) The retrograde method. LAMS, lumen-apposing selfexpandable metal stent. 
go pass the obstruction and the LAMS is deployed from the jejunal side into the stomach. This method reduces the risk of distal flange misdeployment because the stomach is less likely to be pushed away than the jejunum. ${ }^{1,19}$

\section{EUS-guided balloon-occluded GJ bypass method}

A gastroscope is used to place a guidewire in the proximal jejunum bypassing the stricture (Figs. 3C, 4). A shorttype balloon overtube is then placed in the stomach. A novel double balloon-occlusion catheter is passed over the guidewire and the two balloons (20 cm apart) are inflated, obstructing a segment of duodenum and jejunum. The obstructed segment is then filled with contrast material and methylene blue. Direct puncture with LAMS is then performed between the two balloons in this segment of small bowel and the LAMS is deployed. The advantage of this approach is that the jejunum is fixed between the balloons and can prevent migration while the LAMS is deployed; however, this method is not feasible if the jejunum and duodenum are not in close proximity to the gastric wall.

Ongoing studies are currently comparing the different methods for EUS-GE and more evidence is needed before we can establish an endoscopic standard for this procedure. ${ }^{1,19}$ Chen et al. ${ }^{21}$ has compared the direct method versus the balloon assisted method in EUS-GE in a multicenter retrospective study, with results showing significantly shorter procedural time for the direct method, but comparable adverse events, technical and clinical success, reintervention rates and survival.

\section{OUTCOMES}

\section{Duodenal stenting versus surgical $\mathrm{GJ}$}

Multiple studies have compared duodenal stenting versus surgical GJ (both OGJ and LGJ) in the treatment of GOO and have reached quite similar conclusions over the years (Table 1). ${ }^{22}$ Many different factors affect the choice between stenting and surgery, such as patient's physical condition, life expectancy, disease status. Previous studies have found that patient with a longer life expectancy (e.g., $>2$ months in SUSTENT study), surgical GJ should be used. ${ }^{23}$ Other studies found that in patients with better performance status, surgical GJ is preferable as the median survival was significantly shorter after SEMS placement than after GJ ( 189 days vs 293 days, $\mathrm{p}=0.003$ ). ${ }^{24,25}$
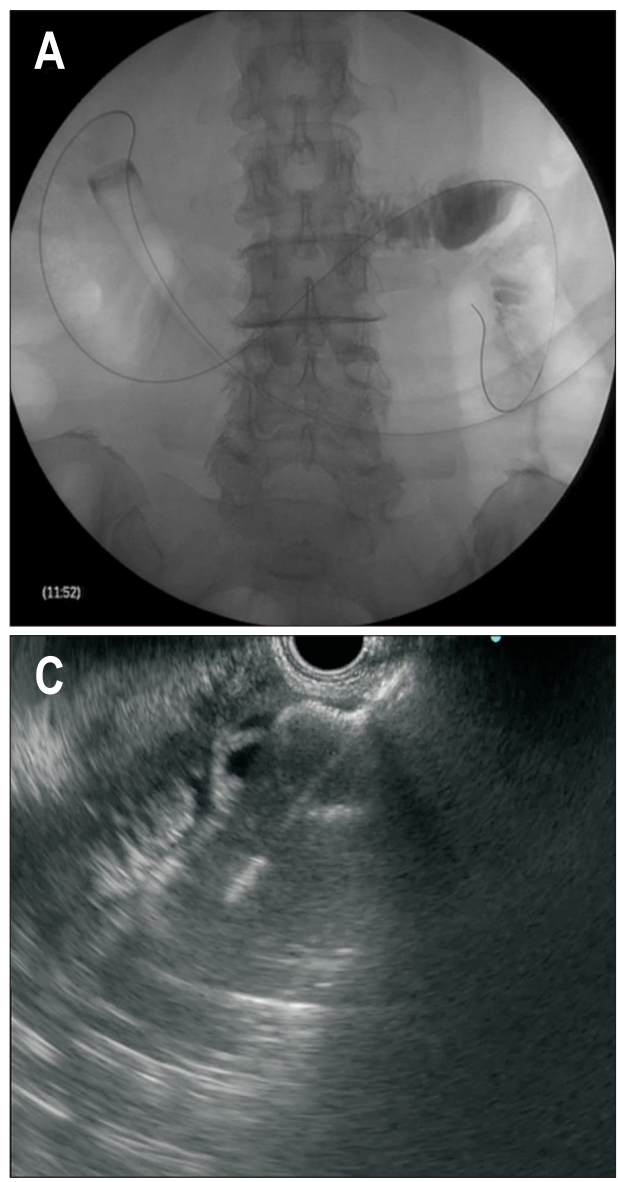
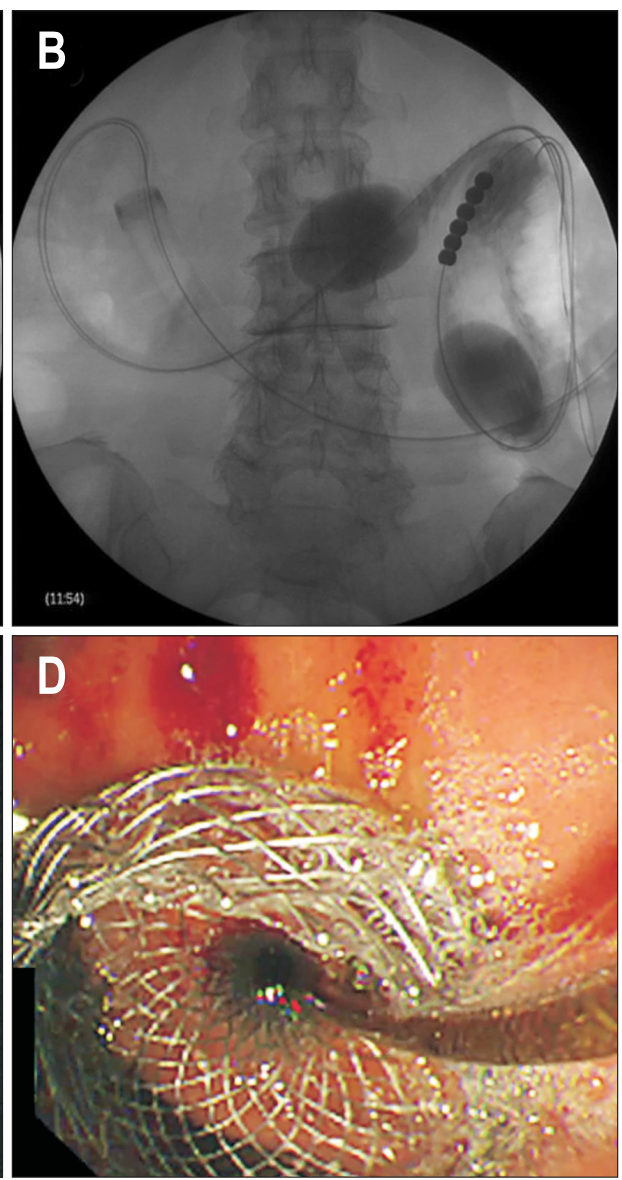

Fig. 4. Endoscopic ultrasonographyguided balloon-occluded gastrojejunostomy bypass. (A) Insertion of the short-type balloon overtube into the stomach. (B) Insertion of the double balloon-occlusion catheter and inflation of the balloons. (C) Deployment of the distal flange of the lumen-apposing self-expandable metal stent (LAMS). (D) Deployment of the proximal flange of the LAMS. 
Table 1. Duodenal Stent versus Gastrojejunostomy

\begin{tabular}{|c|c|c|c|c|c|c|c|c|}
\hline Author (year) & & $\begin{array}{c}\text { No. of } \\
\text { patients }\end{array}$ & $\begin{array}{c}\text { Technical } \\
\text { success, \% }\end{array}$ & $\begin{array}{c}\text { Clinical } \\
\text { success, \% }\end{array}$ & $\begin{array}{l}\text { Time to food } \\
\text { tolerance, day }\end{array}$ & $\begin{array}{c}\text { Hospital stay, } \\
\text { day }\end{array}$ & $\begin{array}{c}\text { Averse event, } \\
\%\end{array}$ & $\begin{array}{c}\text { Reintervention, } \\
\%\end{array}$ \\
\hline \multirow[t]{3}{*}{ Fiori et al. $(2004)^{29}$} & GJ & 9 & 100 & 100 & 6.3 & 10 & 11.1 & \\
\hline & DS & 9 & 100 & 100 & 2.1 & 3.1 & 11.1 & \\
\hline & p-value & & & & $<0.01$ & $<0.01$ & & \\
\hline \multirow[t]{3}{*}{ Mehta et al. $(2006)^{30}$} & GJ & 14 & 100 & 100 & & 11.4 & & \\
\hline & DS & 13 & 92 & 92 & & 5.2 & & \\
\hline & p-value & & NS & NS & & 0.02 & & \\
\hline \multirow[t]{3}{*}{ Jeurnink et al. $(2010)^{23}$} & GJ & 18 & 88 & & 8 & 15 & 0 & \\
\hline & DS & 21 & 76 & & 5 & 7 & 6 in 4 patients & \\
\hline & p-value & & NS & & $<0.01$ & 0.04 & 0.02 & $<0.01$ \\
\hline \multirow[t]{3}{*}{ No et al. $(2013)^{25}$} & GJ & 41 & 97.6 & 95.1 & 5 & 18 & 12.2 & 5.5 \\
\hline & DS & 113 & 95.8 & 87.5 & 2 & 16 & 44.4 & 43 \\
\hline & $\mathrm{p}$-value & & NS & NS & $<0.01$ & NS & $<0.01$ & $<0.01$ \\
\hline \multirow[t]{3}{*}{ Espinel et al. $(2006)^{27}$} & GJ & 17 & & 82.3 & 5 & 11.5 & 17.6 & \\
\hline & DS & 24 & & 100 & 2.4 & 7.1 & 4 & \\
\hline & $\mathrm{p}$-value & & & NS & $<0.01$ & $<0.01$ & & \\
\hline \multirow[t]{3}{*}{ Chandrasegaram et al. $(2012)^{28}$} & GJ & 19 & & & 9 & 25 & & \\
\hline & DS & 26 & & & 2 & 11 & & \\
\hline & $p$-value & & & & $<0.01$ & $<0.01$ & & \\
\hline
\end{tabular}

GJ, gastrojejunostomy; DS, duodenal stent; NS, not significant.

Table 2. Endoscopic Ultrasound Guided Gastroenterostomy versus Duodenal Stent versus Gastrojejunostomy

\begin{tabular}{|c|c|c|c|c|c|c|}
\hline Author (year) & & No. of patients & Technical success, \% & Clinical success, $\%$ & Averse event, $\%$ & Reintervention, \% \\
\hline \multirow[t]{3}{*}{ Chen et al. $(2017)^{36}$} & EUS-GE & 30 & 86.7 & 83.3 & 16.7 & 4.0 \\
\hline & DS & 52 & 94.2 & 67.3 & 11.5 & 28.6 \\
\hline & $\mathrm{p}$-value & & 0.2 & 0.12 & 0.5 & 0.02 \\
\hline \multirow[t]{3}{*}{ Ge et al. $(2019)^{35}$} & EUS-GE & 22 & 100 & 95.8 & 20.8 & 8.3 \\
\hline & DS & 78 & 100 & 76.3 & 40.2 & 32.0 \\
\hline & $\mathrm{p}$-value & & 1.00 & 0.04 & 0.10 & 0.02 \\
\hline \multirow[t]{3}{*}{ Khashab et al. $(2017)^{37}$} & EUS-GE & 30 & 86.7 & 86.7 & 13.3 & 3.4 \\
\hline & DS & 60 & 96.7 & 70 & 18.3 & 43.4 \\
\hline & $\mathrm{p}$-value & & 0.07 & 0.08 & 0.55 & $<0.01$ \\
\hline \multirow[t]{3}{*}{ Perez-Miranda et al. $(2017)^{38}$} & EUS-GE & 29 & 88 & 88 & 12 & \\
\hline & DS & 22 & 100 & 100 & 41 & \\
\hline & $\mathrm{p}$-value & & 0.11 & 0.11 & 0.03 & \\
\hline
\end{tabular}

EUS-GE, endoscopic ultrasound guided gastroenterostomy; DS, duodenal stent.

The presence of hypoalbuminemia in a patient can pose as a risk factor for surgical GJ as it affects wound and anastomosis healing. Presence of carcinomatosis with ascites is also an independent predictive factor for poor clinical success of stent placement. ${ }^{20}$ Meta-analysis has also shown that mean patency duration and survival lengths were significantly longer in the GJ group (169.2 and 193.4 days, respectively), compared to the endoscopic stenting group (96.5 and 119.9 days, respectively), ${ }^{26}$ and therefore if patient is expected to have longer survival and is fit for surgery, GJ should be chosen as choice of treatment.

In previous studies, the outcomes of stenting and surgery were compared. Firstly, stenting is associated with a higher initial clinical success, often measured by how rapid food intake is improved based on a GOO scoring system. ${ }^{23}$
Secondly, stenting offers a shorter length of hospital stay with a mean difference of up to 10 days. ${ }^{27-30}$ Thirdly, cost analysis has also shown that stenting is the significantly cheaper option amongst the two in one American and one Dutch study. ${ }^{31,32}$ Fourthly, some studies have found that the quality of life after stent placement is better, in terms of faster decrease in pain scores, ${ }^{23}$ and significant improvements in dysphagia, eating restrictions, dry mouth and reflux. ${ }^{33,34}$ However, there is no difference in terms of the rate of technical success and median survival.

However, stenting is associated with a higher major complication rate including bleeding and perforation, and a high risk of stent migration. Recurrent obstructive symptoms are common up to $27 \%$, commonly due to stent obstruction commonly due to tumor ingrowth or over 
growth, leading to a higher reintervention rate and poorer longer outcomes. ${ }^{24}$ Reinterventions after stent complications can include endoscopy cleaning of stent, second stent placement or changing to GJ. ${ }^{23}$ Stent patency is significantly lower, even after insertion of a second stent when compared to the surgical group. ${ }^{25}$

On the other hand, complications associated with GJ include intra and postoperative hemorrhage, and dysfunction and leakage of anastomosis. Anastomotic stricture is also a possible complication and requires endoscopic stenting. ${ }^{25}$

\section{EUS-GE versus duodenal stenting}

One retrospective study has found that EUS-GE is associated with a lower rate of stent failure requiring reintervention $(32.0 \%$ vs $8.3 \%, \mathrm{p}=0.021)$ and a higher initial clinical success (96\% vs $76 \%$ ), when compared to duodenal stenting. ${ }^{35}$ In another study by Chen et al., ${ }^{36}$ the authors also reported significantly lower reintervention rates in EUS-GE compared to duodenal stenting (4\% vs $27 \%, \mathrm{p}=0.015)$. Other advantages include fewer adverse events such as lower incidence of stent ingrowth and distal obstruction, however this did not reach a statistical significance. The length of hospital stay and technical success is similar in both methods (Table 2$)^{36}$

\section{EUS-GE versus surgical GJ}

In a study in 2017, higher technical success was found in OGJ (100\% vs $87 \%)$, but clinical success, mean length of hospital stay, rate of GOO recurrence, and mean time to reintervention are all similar. ${ }^{37}$ In another study, significantly more adverse events are found in LGJ when compared to EUS-GE (41\% vs $12 \%, \mathrm{p}=0.03$ ) including ileus, gastroparesis, and anastomotic leak requiring surgery. ${ }^{38}$ This study also found similar technical and clinical success and similar length of hospital stay between the two methods. Other advantages of EUS-GE include shorter procedural time when compared to the surgical approach (Table 2).

\section{CONCLUSION}

In conclusion, with the benefits of endoscopic technique, whilst being able to place a stent away from the tumor, EUS-GE is a promising technique that may provide similar efficacy to surgical GJ and duodenal stenting with lower reintervention rates, reduced adverse events.

\section{CONFLICTS OF INTEREST}

A.Y.B.T. is a consultant for Boston Scientific, Cook, Taewoong and Microtech Medical Corporations. No other potential conflict of interest relevant to this article was reported.

\section{ORICD}

Stephanie Lok Hang Cheung https://orcid.org/0000-0001-6068-6241

Anthony Yuen Bun Teoh https://orcid.org/0000-0002-1885-8035

\section{REFERENCES}

1. Tonozuka R, Tsuchiya T, Mukai S, Nagakawa Y, Itoi T. Endoscopic ultrasonography-guided gastroenterostomy techniques for treatment of malignant gastric outlet obstruction. Clin Endosc 2020;53:510-518.

2. Ojima T, Nakamori M, Nakamura M, Katsuda M, Hayata K, Yamaue H. Laparoscopic gastrojejunostomy for patients with unresectable gastric cancer with gastric outlet obstruction. J Gastrointest Surg 2017;21:1220-1225.

3. Zhang LP, Tabrizian P, Nguyen S, Telem D, Divino C. Laparoscopic gastrojejunostomy for the treatment of gastric outlet obstruction. JSLS 2011;15:169-173.

4. Navarra G, Musolino C, Venneri A, De Marco ML, Bartolotta M. Palliative antecolic isoperistaltic gastrojejunostomy: a randomized controlled trial comparing open and laparoscopic approaches. Surg Endosc 2006;20:1831-1834.

5. Manuel-Vázquez A, Latorre-Fragua R, Ramiro-Pérez C, López-Marcano A, la Plaza-Llamas R, Ramia JM. Laparoscopic gastrojejunostomy for gastric outlet obstruction in patients with unresectable hepatopancreatobiliary cancers: a personal series and systematic review of the literature. World J Gastroenterol 2018;24:1978-1988.

6. Al-Rashedy M, Dadibhai M, Shareif A, et al. Laparoscopic gastric bypass for gastric outlet obstruction is associated with smoother, faster recovery and shorter hospital stay compared with open surgery. J Hepatobiliary Pancreat Surg 2005; $12: 474-478$

7. Topazian M, Ring E, Grendell J. Palliation of obstructing gastric cancer with steel mesh, self-expanding endoprostheses. Gastrointest Endosc 1992;38:58-60.

8. Dormann A, Meisner S, Verin N, Wenk Lang A. Selfexpanding metal stents for gastroduodenal malignancies: systematic review of their clinical effectiveness. Endoscopy 2004;36:543-550. 
9. Boškoski I, Tringali A, Familiari P, Mutignani M, Costamagna G. Self-expandable metallic stents for malignant gastric outlet obstruction. Adv Ther 2010;27:691-703.

10. Hirdes MM, Vleggaar FP, de Beule M, Siersema PD. In vitro evaluation of the radial and axial force of self-expanding esophageal stents. Endoscopy 2013;45:997-1005.

11. Tringali A, Giannetti A, Adler DG. Endoscopic management of gastric outlet obstruction disease. Ann Gastroenterol 2019;32:330-337.

12. Hamada T, Hakuta R, Takahara N, et al. Covered versus uncovered metal stents for malignant gastric outlet obstruction: systematic review and meta-analysis. Dig Endosc 2017;29:259-271.

13. Kim CG, Choi IJ, Lee JY, et al. Covered versus uncovered self-expandable metallic stents for palliation of malignant pyloric obstruction in gastric cancer patients: a randomized, prospective study. Gastrointest Endosc 2010;72:25-32.

14. Maetani I, Mizumoto Y, Shigoka H, et al. Placement of a triple-layered covered versus uncovered metallic stent for palliation of malignant gastric outlet obstruction: a multicenter randomized trial. Dig Endosc 2014;26:192-199.

15. Potz BA, Miner TJ. Surgical palliation of gastric outlet obstruction in advanced malignancy. World J Gastrointest Surg 2016;8:545-555.

16. Fritscher-Ravens A, Mosse CA, Mills TN, Mukherjee D, Park PO, Swain P. A through-the-scope device for suturing and tissue approximation under EUS control. Gastrointest Endosc 2002;56:737-742.

17. Irani S, Itoi T, Baron TH, Khashab M. EUS-guided gastroenterostomy: techniques from East to West. VideoGIE 2019;5:48-50.

18. McCarty TR, Garg R, Thompson CC, Rustagi T. Efficacy and safety of EUS-guided gastroenterostomy for benign and malignant gastric outlet obstruction: a systematic review and meta-analysis. Endosc Int Open 2019;7:E1474-E1482.

19. Wang G, Liu X, Wang S, Ge N, Guo J, Sun S. Endoscopic ultrasound-guided gastroenterostomy: a promising alternative to surgery. J Transl Int Med 2019;7:93-99.

20. Jeon HH, Park CH, Park JC, et al. Carcinomatosis matters: clinical outcomes and prognostic factors for clinical success of stent placement in malignant gastric outlet obstruction. Surg Endosc 2014;28:988-995.

21. Chen YI, Kunda R, Storm AC, et al. EUS-guided gastroenterostomy: a multicenter study comparing the direct and balloon-assisted techniques. Gastrointest Endosc 2018;87:12151221.

22. Nagaraja V, Eslick GD, Cox MR. Endoscopic stenting versus operative gastrojejunostomy for malignant gastric outlet obstruction-a systematic review and meta-analysis of randomized and non-randomized trials. J Gastrointest Oncol 2014;5:92-98.
23. Jeurnink SM, Steyerberg EW, van Hooft JE, et al. Surgical gastrojejunostomy or endoscopic stent placement for the palliation of malignant gastric outlet obstruction (SUSTENT study): a multicenter randomized trial. Gastrointest Endosc 2010;71:490-499.

24. Mintziras I, Miligkos M, Wächter S, Manoharan J, Bartsch DK. Palliative surgical bypass is superior to palliative endoscopic stenting in patients with malignant gastric outlet obstruction: systematic review and meta-analysis. Surg Endosc 2019;33:3153-3164.

25. No JH, Kim SW, Lim CH, et al. Long-term outcome of palliative therapy for gastric outlet obstruction caused by unresectable gastric cancer in patients with good performance status: endoscopic stenting versus surgery. Gastrointest Endosc 2013;78:55-62.

26. Jang S, Stevens T, Lopez R, Bhatt A, Vargo JJ. Superiority of gastrojejunostomy over endoscopic stenting for palliation of malignant gastric outlet obstruction. Clin Gastroenterol Hepatol 2019;17:1295-1302.

27. Espinel J, Sanz O, Vivas S, et al. Malignant gastrointestinal obstruction: endoscopic stenting versus surgical palliation. Surg Endosc 2006;20:1083-1087.

28. Chandrasegaram MD, Eslick GD, Mansfield CO, et al. Endoscopic stenting versus operative gastrojejunostomy for malignant gastric outlet obstruction. Surg Endosc 2012;26:323329.

29. Fiori E, Lamazza A, Volpino P, et al. Palliative management of malignant antro-pyloric strictures. Gastroenterostomy vs. endoscopic stenting: a randomized prospective trial. Anticancer Res 2004;24:269-271.

30. Mehta S, Hindmarsh A, Cheong E, et al. Prospective randomized trial of laparoscopic gastrojejunostomy versus duodenal stenting for malignant gastric outflow obstruction. Surg Endosc 2006;20:239-242.

31. Roy A, Kim M, Christein J, Varadarajulu S. Stenting versus gastrojejunostomy for management of malignant gastric outlet obstruction: comparison of clinical outcomes and costs. Surg Endosc 2012;26:3114-3119.

32. Jeurnink SM, Polinder S, Steyerberg EW, Kuipers EJ, Siersema PD. Cost comparison of gastrojejunostomy versus duodenal stent placement for malignant gastric outlet obstruction. J Gastroenterol 2010;45:537-543.

33. Schmidt C, Gerdes H, Hawkins W, et al. A prospective observational study examining quality of life in patients with malignant gastric outlet obstruction. Am J Surg 2009;198:9299.

34. Guo JJ, Liang WX, Zhang T. A prospective comparative study of three treatment options in patients with malignant gastric outlet obstruction. Zhonghua Wei Chang Wai Ke Za Zhi 2010;13:598-600.

35. Ge PS, Young JY, Dong W, Thompson CC. EUS-guided 
gastroenterostomy versus enteral stent placement for palliation of malignant gastric outlet obstruction. Surg Endosc 2019;33:3404-3411.

36. Chen YI, Itoi T, Baron TH, et al. EUS-guided gastroenterostomy is comparable to enteral stenting with fewer reinterventions in malignant gastric outlet obstruction. Surg Endosc 2017;31:2946-2952.

37. Khashab MA, Bukhari M, Baron TH, et al. International multicenter comparative trial of endoscopic ultrasonography-guided gastroenterostomy versus surgical gastrojejunostomy for the treatment of malignant gastric outlet obstruction. Endosc Int Open 2017;5:E275-E281.

38. Perez-Miranda M, Tyberg A, Poletto D, et al. EUS-guided gastrojejunostomy versus laparoscopic gastrojejunostomy: an international collaborative study. J Clin Gastroenterol 2017;51:896-899. 